\title{
Evaluation of drug information resources for drug- ethanol and drug-tobacco interactions
}

\author{
Robert D. Beckett; Curtis D. Stump; Megan A. Dyer
}

See end of article for authors' affiliations.

\begin{abstract}
Objective: The research evaluated point-of-care drug interaction resources for scope, completeness, and consistency in drug-ethanol and drug-tobacco content.
\end{abstract}

\begin{abstract}
Methods: In a cross-sectional analysis, 2 independent reviewers extracted data for 108 clinically relevant interactions using 7 drug information resources (Clinical Pharmacology Drug Interaction Report, Facts \& Comparisons eAnswers, Lexicomp Interactions, Micromedex Drug Interactions, Drug Interactions Analysis and Management, Drug Interaction Facts, and Stockley's Drug Interactions). Scope (presence of an entry), completeness (content describing mechanism, clinical effects, severity, level of certainty, and course of action for each present interaction; up to 1 point per assessed item for a total possible score of 5 points), and consistency (similarity among resources) were evaluated.
\end{abstract}

Results: Fifty-three drug-ethanol and 55 drug-tobacco interactions were analyzed. Drug-ethanol interaction entries were most commonly present in Lexicomp (84.9\%), Clinical Pharmacology (83.0\%), and Stockley's Drug Interactions (73.6\%), compared to other resources $(p<0.05)$. Drug-tobacco interactions were more often covered in Micromedex (56.4\%), Stockley's Drug Interactions (56.4\%), Drug Interaction Facts (43.6\%), and Clinical Pharmacology (41.8\%) ( $p<0.001)$. Overall completeness scores were higher for Lexicomp, Micromedex, Drug Interaction Facts, and Facts \& Comparisons (median 5/5 points, interquartile range [IQR] 5 to $5, p<0.001$ ) for drug-ethanol and for Micromedex (median 5/5 points, IQR 5 to 5, $p<0.05$ ) for drugtobacco, compared to other resources. Drug Interaction Facts and Micromedex were among the highest scoring resources for both drug-ethanol $(73.7 \%, 68.6 \%)$ and drug-tobacco $(75.0 \%, 32.3 \%)$ consistency.

Conclusions: Scope and completeness were high for drug-ethanol interactions, but low for drug-tobacco interactions. Consistency was highly variable across both interaction types.

\section{INTRODUCTION}

In the United States, an estimated $88 \%$ of the population over the age of 18 reported consuming ethanol at some point in their lives $(69 \%$ in the past 12 months), and about 51,000,000 adults were current smokers as of 2016 [1, 2]. Ethanol and tobacco have the potential to interact with many prescription and over-the-counter medications that patients may be taking on a daily basis [3,4]. Drug interactions are a major contributor to adverse drug events, which occur in about $6 \%$ of hospitalized patients [5] and are responsible for about 4.5 million outpatient visits each year [6]. Between 33\% and $58 \%$ of inpatient adverse drug reactions and $42 \%$ and $62 \%$ of outpatient adverse drug reactions are likely preventable, with drug interactions identified as a key etiology behind adverse drug reactions [7].

Ethanol and tobacco have the potential to interact with therapeutic drugs through several mechanisms [3, 4]. Alcohol dehydrogenase (CYP2E1) is a metabolizing enzyme for ethanol and is inhibited by ethanol; thus, ethanol can interact with substrates, inhibitors, or inducers of CYP2E1 [3]. It can also contribute to additive central nervous system (CNS) depressant effects when used with other CNS depressants (e.g., benzodiazepines, opioids), which can increase a patient's risk for sedation and psychomotor impairment. Most drugethanol interactions are due to the latter mechanism. The large number of compounds found in 
cigarette smoke induce CYP1A1, 1A2, and 2E1, and suppress CYP2A6, potentially resulting in altered metabolism of drugs affected by these enzymes.

Although there are numerous drug-ethanol and drug-tobacco interactions that may be clinically significant and essential to manage in practice $[3,4$, $8,9]$, previous evaluations of point-of-care resources have not examined these interaction types [10-13]. The objective of this study was to evaluate point-ofcare drug interaction resources for scope, completeness, and consistency in drug-ethanol and drug-tobacco content.

\section{METHODS}

This was an observational, cross-sectional analysis of seven drug information resources that pharmacists and other health care professionals commonly use when managing drug interactions. Study methods are outlined in Figure 1. The seven resources included four electronic drug information databases (Clinical Pharmacology Drug Interaction Report
[14], Facts \& Comparisons eAnswers [15], Lexicomp Interactions [16], and Micromedex Drug Interactions [17]) and three print reference books (Drug Interactions Analysis and Management [18], Drug Interaction Facts [19], and Stockley's Drug Interactions [20]). The resources were selected through a review of Basic Resources for Pharmacy Education [21], published by the American Association of Colleges of Pharmacy (AACP) Library and Information Sciences section (LIS); a seminal book chapter outlining recommended interactions resources that are essential for drug information practice [22]; and a review of similar studies $[10,13]$.

To compare the seven resources, a sample of drug-ethanol and drug-tobacco interactions was selected. Specific drug-alcohol and drug-tobacco interactions were identified through a review of the Indiana University Department of Medicine Flockhart Table [23] and a PubMed search for systematic reviews describing the most clinically relevant interactions of each type [3, 4, 8, 9]. Drugtobacco interactions were defined as any interaction between a medication and the components of

Figure 1 Study methods

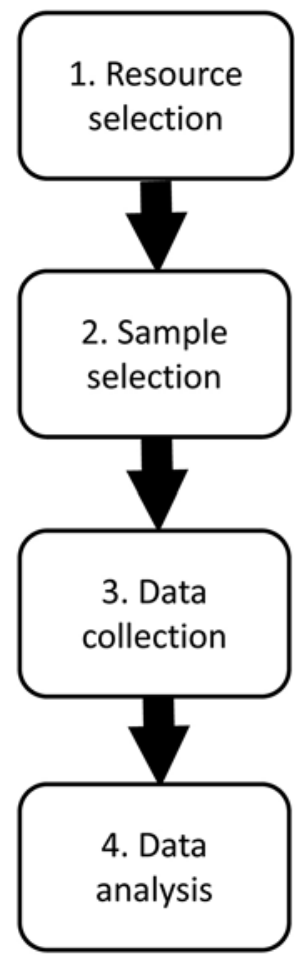

- Consulted Basic Resources for Pharmacy Education [21]

- Reviewed Drug Information: A Guide for Pharmacists [22]

- Evaluated previous related studies $[10,13]$

Searched the literature for clinically relevant interactions

- Consulted subject matter experts to validate sample

- All investigators gathered data for the first several interactions

- Two investigators gathered data for remaining interactions

- Discrepancies resolved on consensus with third investigator

- Calculated scope and completeness scores

- Coded severity and course of action using standard terms

- Calculated consistency scores using severity and course of action

- Conducted inferential statistics to develop tiers 
cigarette smoke, as opposed to specific interactions involving nicotine. The initial list of potential interactions for evaluation was then reviewed by two subject matter experts, a clinical pharmacy specialist in psychiatry and a drug information pharmacist, to ensure all potential interactions were clinically relevant and to identify additional interactions that should be included. None of the evaluated resources were consulted in developing the list to avoid biasing results toward a specific resource.

Several methods were used to promote valid data collection. The reviewers were provided with directions in an orientation session to the project and a data collection form to promote consistency. The data collection form was a shared, cloud-based spreadsheet document that could be updated in real time by multiple users. Data collection for the first several interactions was reviewed by all three investigators to build a common approach. Two independent reviewers then collected data for each of the remaining interactions that were included in the final list. Any discrepancies between the two independent reviewers, thereafter, were resolved by consensus with the third investigator; fewer than ten cases required consensus.

Based on previous studies [10-13, 24-27], scope, completeness, and consistency were the evaluated endpoints used to assess the study objectives. Figure 2 provides a full description of how each endpoint was calculated, along with an example. First, scope was defined as presence of an entry and calculated simply as the percentage of sample interactions that had an entry in each resource.

Five items were extracted for each interaction from each resource where an entry was present:

- Mechanism was defined as the proposed pharmacokinetic or pharmacodynamic way the interaction transpires.

- Clinical effects were defined as the potential signs and symptoms resulting from the interaction, as well as patient outcomes.

- Severity was defined as the degree of clinical impact on the patient if the interaction were to occur.

- Level of certainty was defined as the likelihood of the interaction actually occurring, considering how well it is documented in the resource.

- Finally, course of action was defined as the recommended necessary actions if a patient were to present with simultaneous prescriptions or medication orders for the interaction.

Completeness was defined as the percentage of interactions with an entry that provided specified content describing each of the extracted items (i.e., mechanism, clinical effects, severity, level of certainty, course of action). An overall completeness score was calculated for each interaction for each resource with an entry by awarding one point for each of the five assessed items and summing the points. Data were gathered and entered into the data collection form over a three-month period in early 2018. Collected data and definitions align with a previous study [10].

Figure 2 Full description of each endpoint along with an example

\begin{tabular}{|c|c|c|c|}
\hline Endpoint & Calculation & Example & Score \\
\hline Scope $=$ & Number of interactions with an entry & 45 drug-ethanol interactions with an entry on Lexicomp & $=84.9 \%$ \\
\hline & & & \\
\hline \multirow{2}{*}{ Completeness $($ Mechanism $)=$} & Number of interactions with specified content & 38 drug-ethanol interactions with specified content on Lexicomp & \multirow{2}{*}{$=84.4 \%$} \\
\hline & Total number of interactions with an entry & 45 drug-ethanol interactions with an entry on Lexicomp & \\
\hline \multirow[b]{2}{*}{ Completeness (Clinical Effects) $=$} & Number of interactions with specified content & 45 drug-ethanol interactions with specified content on Lexicomp & \multirow[b]{2}{*}{$=100 \%$} \\
\hline & Total number of interactions with an entry & 45 drug-ethanol interactions with an entry on Lexicomp & \\
\hline \multirow{2}{*}{ Completeness (Severity) $=$} & Number of interactions with specified content & 45 drug-ethanol interactions with specified content on Lexicomp & \multirow{2}{*}{$=100 \%$} \\
\hline & Total number of interactions with an entry & 45 drug-ethanol interactions with an entry on Lexicomp & \\
\hline \multirow{2}{*}{ Completeness (Level of Severity) $=$} & Number of interactions with specified content & 45 drug-ethanol interactions with specified content on Lexicomp & \multirow[b]{2}{*}{$=100 \%$} \\
\hline & Total number of interactions with an entry & 45 drug-ethanol interactions with an entry on Lexicomp & \\
\hline \multirow[b]{2}{*}{ Completeness (Course of Action) $=$} & Number of interactions with specified content & 45 drug-ethanol interactions with specified content on Lexicomp & \multirow{2}{*}{$=100 \%$} \\
\hline & Total number of interactions with an entry & 45 drug-ethanol interactions with an entry on Lexicomp & \\
\hline Completeness $($ Overall $)=$ & $\begin{array}{l}1 \text { point for each completeness item for a total of } 5 \\
\text { possible points per interaction per resource, then } \\
\text { calculate median value }\end{array}$ & $\begin{array}{l}38 \text { drug-ethanol interactions with a score of } 5 / 5 \text { on Lexicomp, } 7 \text { drug- } \\
\text { ethanol interactions with a score of } 4 / 5 \text { on Lexicomp }\end{array}$ & $=5$ \\
\hline \multirow[b]{2}{*}{ Consistency (Severity) $=$} & Number of interactions with content similar to the majority & 34 drug-ethanol interactions on Lexicomp with consistent severity content & \multirow{2}{*}{$-=75.6 \%$} \\
\hline & Total number of interactions with severity content & 45 drug-ethanol interactions on Lexicomp with severity content & \\
\hline Consistency (Course of Action) $=$ & $\begin{array}{l}\text { Number of interactions with content similar to the majority } \\
\text { Total number of interactions with course of action content }\end{array}$ & $\begin{array}{l}25 \text { drug-ethanol interactions on Lexicomp with consistent severity content } \\
45 \text { drug-ethanol interactions on Lexicomp with severity content }\end{array}$ & $=55.6 \%$ \\
\hline
\end{tabular}


Content for severity and course of action, as the most objective extracted data points, were used as markers to examine consistency among the seven resources. For each interaction, the severity rating for each interaction in each resource was coded as minor, moderate, major, or severe/contraindicated. Consistency scores were calculated as the percentage of severity ratings that were similar to the majority rating from the available sample of resources. A second consistency score was calculated using recommended course of action. Available course of action recommendations were coded as no action needed, monitor, adjust some component of therapy, or avoid the combination, with consistency scores calculated in the same manner as for severity ratings. Resources were omitted from consistency calculations if they had three or fewer entries.

Descriptive statistics, namely, number and percentages for categorical data (i.e., scope scores, completeness items, consistency scores) and median with interquartile range (IQR) for overall completeness scores (given lack of expectation for normal distribution of ordinal data),were primarily used to illustrate results.

To help guide users toward the best resources in terms of scope, completeness, and consistency, we used inferential statistics to group resources into tiers for both drug-ethanol and drug-tobacco content in terms of each of the 3 qualities. The scope, overall completeness, and consistency (for course of action content) scores for each resource were compared to the highest scoring resource in each category. This was done in a stepwise approach guided by similar studies of electronic drug information resources [10, 25]. Resources were grouped into a lower tier when the difference in scores, compared to the highest scoring resource in the next highest tier, was statistically significant, using a 2-sided alpha of 0.05 . Resources were omitted from tier calculations if 3 or fewer entries were available for analysis.

Data were treated as paired, since the same interactions were evaluated across the 7 resources; thus, the McNemar test was used to build the scope and consistency tiers (categorical data) and the Wilcoxon signed-rank test was used to build the overall completeness tiers (ordinal data). Inferential statistics were conducted with IBM SPSS Statistics, version 24 [28]. Upon consultation with an institutional review board (IRB) member, it was determined that the study did not involve human subjects and that IRB review was not necessary.

\section{RESULTS}

The initial search identified 37 drug-ethanol and 53 drug-tobacco interactions for analysis. Following review of the initial list by subject matter experts, we added 16 drug-ethanol and 2 drug-tobacco interactions, yielding a total of 108 interactions. The final sample is found in Table 1.

Scope score results are described in Table 2. Of the total sample of 53 drug-ethanol interactions, scope score ranged from $20.8 \%$ (Drug Interactions Analysis and Management) to $84.9 \%$ (Lexicomp). Of the total sample of 55 drug-tobacco interactions, scope score ranged from $10.9 \%$ (Facts \& Comparisons) to $56.4 \%$ (Micromedex, Stockley's Drug Interactions). No drug-tobacco interactions were found in Lexicomp, and we confirmed with a company representative that Lexicomp does not index drug-tobacco interactions (although they did index 3 drug-nicotine interactions at the time of writing).

Completeness results are described in Table 3. For drug-ethanol interactions, information was most often provided for clinical effects (ranging from $86.4 \%$, Clinical Pharmacology, to $100.0 \%$, Facts \& Comparisons, Lexicomp, Micromedex, Drug Interactions Analysis and Management) and course of action (ranging from $76.9 \%$, Stockley's Drug Interactions, to $100.0 \%$, Facts \& Comparisons, Lexicomp, Micromedex, Drug Interactions Analysis and Management). Clinical effects (ranging from $13.0 \%$, Clinical Pharmacology, to $100.0 \%$, Micromedex and Drug Interactions Analysis and Management) and course of action (ranging from $32.0 \%$, Drug Interaction Facts, to $100.0 \%$, Facts \& Comparisons, Micromedex, Drug Interactions Analysis and Management) were also the highest scoring items for drug-tobacco interactions. 
Beckett et al.

DOI: dx.doi.org/10.5195/jmla.2019.549

Table 1 Sample of interactions for evaluation

\begin{tabular}{|c|c|}
\hline Drug-ethanol $(n=53)$ & Drug-tobacco $(n=55)$ \\
\hline Abacavir & Acetaminophen \\
\hline Acetaminophen & Alprazolam \\
\hline Alprazolam & Artemether \\
\hline Amitriptyline & Caffeine \\
\hline Aspirin & Carbamazepine \\
\hline Chlordiazepoxide & Chlordiazepoxide \\
\hline Chlorzoxazone & Chlorpromazine \\
\hline Cimetidine & Chlorzoxazone \\
\hline Clobazam & Clobazam \\
\hline Clonazepam & Clomipramine \\
\hline Codeine & Clorazepate \\
\hline Diazepam & Clozapine \\
\hline Disulfiram & Codeine \\
\hline Efavirenz & Cyclobenzaprine \\
\hline Enflurane & Dexamethasone \\
\hline Erythromycin & Diazepam \\
\hline Eszopiclone & Duloxetine \\
\hline Ezogabine & Enflurane \\
\hline Felodipine & Estradiol \\
\hline Fentanyl & Flecainide \\
\hline Flurazepam & Fluvoxamine \\
\hline Fluvoxamine & Haloperidol \\
\hline Fomepizole & Halothane \\
\hline Gabapentin & Heparin \\
\hline Halothane & Imipramine \\
\hline Hydrocodone & Insulin \\
\hline Hydromorphone & Isoflurane \\
\hline Isoflurane & Lidocaine \\
\hline Lorazepam & Melatonin \\
\hline Maraviroc & Methoxasalen \\
\hline Metformin & Methoxyflurane \\
\hline Methadone & Mexiletine \\
\hline Methamphetamine & Mirtazapine \\
\hline Methoxyflurane & Nabumetone \\
\hline
\end{tabular}

\begin{tabular}{|l|l|}
\hline Drug-ethanol $\mathbf{( n = 5 3 )}$ & Drug-tobacco $(\mathbf{n}=55)$ \\
\hline Methylphenidate & Naproxen \\
Metronidazole & Nortriptyline \\
Midazolam & Olanzapine \\
Morphine & Ondansetron \\
Nifedipine & Phenacetin \\
Oxazepam & Propranolol \\
Oxycodone & Ramelteon \\
Pregabalin & Riluzole \\
Procainamide & Ropinirole \\
Sevoflurane & Ropivacaine \\
Sodium oxybate & Selegiline \\
Temazepam & Sevoflurane \\
Tetracycline & Tacrine \\
Tramadol & Theophylline \\
Triazolam & Tizanidine \\
Varenicline & Tranylcypromine \\
Verapamil & Triamterene \\
Zaleplon & Verapamil \\
Zolpidem & Warfarin \\
& Zileuton \\
& Zolmitriptan \\
\hline
\end{tabular}

Table 2 Scope scores

\begin{tabular}{|l|ccc|c|c|}
\hline \multirow{2}{*}{ Resource } & \multicolumn{2}{|c|}{$\begin{array}{c}\text { Drug-ethanol } \\
\text { (n=53) }\end{array}$} & \multicolumn{2}{c|}{$\begin{array}{c}\text { Drug-tobacco } \\
\text { (n=55) }\end{array}$} \\
\cline { 2 - 5 } & $\mathbf{n}$ & $\%$ & \multicolumn{1}{c|}{$\mathbf{n}$} & $\%$ \\
\hline CP & 44 & $83.0 \%$ & 23 & $41.8 \%$ \\
FC & 37 & $69.8 \%$ & 6 & $10.9 \%$ \\
LC & 45 & $84.9 \%$ & 0 & - \\
MM & 35 & $66.0 \%$ & 31 & $56.4 \%$ \\
DIAM & 11 & $20.8 \%$ & 12 & $21.8 \%$ \\
DIF & 21 & $39.6 \%$ & 24 & $43.6 \%$ \\
SDI & 39 & $73.6 \%$ & 31 & $56.4 \%$ \\
\hline
\end{tabular}

CP: Clinical Pharmacology; FC: Facts \& Comparisons; LC: Lexicomp; MM: Micromedex; DIAM: Drug Interactions Analysis and Management; DIF: Drug Interaction Facts; SDI: Stockley's Drug Interactions. 
Table 3 Completeness results for interactions with entries

\begin{tabular}{|c|c|c|c|c|c|c|c|c|c|c|c|c|}
\hline \multirow[b]{2}{*}{ Resource } & \multicolumn{2}{|c|}{ Mechanism } & \multicolumn{2}{|c|}{$\begin{array}{l}\text { Clinical } \\
\text { effects }\end{array}$} & \multicolumn{2}{|c|}{ Severity } & \multicolumn{2}{|c|}{$\begin{array}{l}\text { Level of } \\
\text { certainty }\end{array}$} & \multicolumn{2}{|c|}{$\begin{array}{c}\text { Course of } \\
\text { action }\end{array}$} & \multicolumn{2}{|c|}{$\begin{array}{c}\text { Overall } \\
\text { completeness }\end{array}$} \\
\hline & $\mathbf{n}$ & $\%$ & $\mathbf{n}$ & $\%$ & $\mathbf{n}$ & $\%$ & $\mathbf{n}$ & $\%$ & $\mathbf{n}$ & $\%$ & median & IQR \\
\hline \multicolumn{13}{|c|}{ Drug-ethanol interactions } \\
\hline $\mathrm{CP}(\mathrm{n}=44)$ & 41 & $93.2 \%$ & 38 & $86.4 \%$ & 44 & $100.0 \%$ & 1 & $2.3 \%$ & 38 & $86.4 \%$ & 4 & 3.75 to 4 \\
\hline $\mathrm{FC}(\mathrm{n}=37)$ & 34 & $91.9 \%$ & 37 & $100.0 \%$ & 37 & $100.0 \%$ & 37 & $100.0 \%$ & 37 & $100.0 \%$ & 5 & 5 to 5 \\
\hline $\mathrm{LC}(\mathrm{n}=45)$ & 38 & $84.4 \%$ & 45 & $100.0 \%$ & 45 & $100.0 \%$ & 45 & $100.0 \%$ & 45 & $100.0 \%$ & 5 & 5 to 5 \\
\hline $\mathrm{MM}(\mathrm{n}=35)$ & 31 & $88.6 \%$ & 35 & $100.0 \%$ & 35 & $100.0 \%$ & 35 & $100.0 \%$ & 35 & $100.0 \%$ & 5 & 5 to 5 \\
\hline $\operatorname{DIAM}(\mathrm{n}=11)$ & 10 & $90.9 \%$ & 11 & $100.0 \%$ & 1 & $9.1 \%$ & 2 & $18.2 \%$ & 11 & $100.0 \%$ & 3 & 3 to 3.5 \\
\hline DIF $(n=21)$ & 19 & $90.5 \%$ & 19 & $90.5 \%$ & 21 & $100.0 \%$ & 21 & $100.0 \%$ & 19 & $90.5 \%$ & 5 & 5 to 5 \\
\hline SDI $(n=39)$ & 32 & $82.1 \%$ & 38 & $97.4 \%$ & 2 & $5.1 \%$ & 8 & $20.5 \%$ & 30 & $76.9 \%$ & 3 & 2 to 3 \\
\hline \multicolumn{13}{|c|}{ Drug-tobacco interactions } \\
\hline $\mathrm{CP}(\mathrm{n}=23)$ & 21 & $91.3 \%$ & 3 & $13.0 \%$ & 23 & $100.0 \%$ & 0 & - & 15 & $65.2 \%$ & 3 & 2 to 3 \\
\hline $\mathrm{FC}(\mathrm{n}=6)$ & 0 & - & 5 & $83.3 \%$ & 6 & $100.0 \%$ & 0 & - & 6 & $100.0 \%$ & 3 & 3 to 3 \\
\hline $\operatorname{MM}(n=31)$ & 31 & $100.0 \%$ & 31 & $100.0 \%$ & 31 & $100.0 \%$ & 31 & $100.0 \%$ & 31 & $100.0 \%$ & 5 & 5 to 5 \\
\hline $\operatorname{DIAM}(\mathrm{n}=12)$ & 11 & $91.7 \%$ & 12 & $100.0 \%$ & 1 & $8.3 \%$ & 3 & $25.0 \%$ & 12 & $100.0 \%$ & 3 & 3 to 3.25 \\
\hline DIF $(n=25)$ & 21 & $84.0 \%$ & 24 & $96.0 \%$ & 0 & - & 3 & $12.0 \%$ & 8 & $32.0 \%$ & 2 & 2 to 3 \\
\hline SDI $(n=31)$ & 27 & $87.1 \%$ & 30 & $96.8 \%$ & 2 & $6.5 \%$ & 11 & $35.5 \%$ & 24 & $77.4 \%$ & 3 & 3 to 3 \\
\hline
\end{tabular}

IQR: Interquartile range; CP: Clinical Pharmacology; FC: Facts \& Comparisons; LC: Lexicomp; MM: Micromedex; DIAM: Drug Interactions Analysis and Management; DIF: Drug Interaction Facts; SDI: Stockley’s Drug Interactions.

Level of certainty was the lowest scoring item for both drug-ethanol interactions (ranging from $2.3 \%$, Clinical Pharmacology, to $100.0 \%$, Facts \& Comparisons, Lexicomp, Micromedex, Drug Interaction Facts) and drug-tobacco interactions (ranging from 0, Clinical Pharmacology, Facts \& Comparisons, to $100.0 \%$, Micromedex).

Overall completeness scores ranged from a median of 3 (IQR 2 to 3, Stockley's Drug Interactions) to 5 (IQR 5 to 5, Facts \& Comparisons, Lexicomp, Micromedex, Drug Interaction Facts) for drug-ethanol interactions and 2 (IQR 2 to 3, Clinical Pharmacology, Drug Interaction Facts) to 5 (IQR 5 to 5, Micromedex) for drug-tobacco interactions.

Consistency of drug-ethanol interaction information, when assessed using severity ratings, was highest with Lexicomp (75.6\%), followed by Drug Interaction Facts (71.4\%), Micromedex (68.6\%), Facts \& Comparisons (51.4\%), and Clinical Pharmacology (36.4\%). However, when assessed using course of action, it was highest with
Micromedex (82.9\%), followed by Clinical Pharmacology (81.6\%), Drug Interaction Facts (73.7\%), Facts \& Comparisons (56.8\%), Stockley's Drug Interactions (56.7\%), and Lexicomp (55.6\%). For drug-tobacco interactions, consistency scores could only be reported for Micromedex (35.5\%) and Clinical Pharmacology (30.4\%) for severity. When assessed using course of action, drug-tobacco consistency scores were highest for Drug Interaction Facts $(75.0 \%)$, followed by Stockley's Drug Interactions (50.0\%), Drug Interaction Analysis and Management (41.7\%), and Micromedex (32.3\%).

Results of the tier analysis are described in Table 4. Depending on the category, resources were grouped into two to four tiers, based on scores for scope, overall completeness, and consistency. For drug-ethanol interactions, Lexicomp placed in the highest tier for both scope and completeness; whereas for drug-tobacco interactions, Micromedex placed in the highest tier for both scope and completeness. For consistency (in terms of course of 
action, which had more available data points), Micromedex and Drug Interaction Facts placed in the highest tier for both interaction types.

\section{DISCUSSION}

This evaluation identified that clinically relevant drug-ethanol interactions were most commonly present in Lexicomp, Clinical Pharmacology, and Stockley's Drug Interactions, whereas drug-tobacco interactions were more commonly identified in the latter two resources as well as Micromedex and Drug Interaction Facts. Lexicomp, Micromedex, Drug Interaction Facts, and Facts \& Comparisons provided the most complete information regarding drugethanol interactions, but Micromedex alone provided complete drug-tobacco information. It should be noted that drug-ethanol interaction information scored higher for nearly all resources in terms of scope (except for Drug Interaction Facts) and completeness (except for Micromedex and Stockley's Drug Interactions), when compared to drug-tobacco information. Consistency among resources was highly variable, with Micromedex and Drug Interaction Facts providing good consistency for both interaction types. There were no substantial differences in scores for electronic versus print resources, when taken as a whole.

Notably, there was no single resource that scored in the highest tier across scope, completeness, and consistency for both interaction types, emphasizing the need for using multiple resources on interactions in practice settings, where pharmacists and other health care professionals rely on such resources at the point of care, as well as in library collections that serve health care professions and educational institutions. Each resource had distinct strengths and limitations depending on interaction type and information of interest, and results from this study can help direct information professionals and users to the higher quality resources depending on specific needs. For example, Micromedex stood out for having the best coverage of drug-tobacco interactions, complete information across assessed items (e.g., mechanism, clinical effects) for both interaction types, and among the highest consistency scores. However, Clinical Pharmacology, Lexicomp, and Stockley's Drug Interactions covered more drug-ethanol interactions.

We also noted that Facts \& Comparisons, Lexicomp, and Drug Interaction Facts had complete analysis of drug-ethanol interactions, similar to Micromedex. Despite having among the strongest scope and completeness scores for drug-ethanol interactions, Lexicomp notably did not address drug-tobacco interactions.

Differences among resources (especially for Drug Interactions Analysis and Management and Stockley's Drug Interactions), in terms of completeness, tended to be driven by deficiencies in severity and level of certainty information. Drug Interaction Facts, in particular, only addressed drugtobacco interactions in a single appendix table, which could contribute to lack of completeness in this area. In addition to helping guide information professionals and users, these results can aid in focusing educational instruction on appropriate use of these resources and help guide collection management during times of budget constraints.

Table 4 Tier analysis

\begin{tabular}{|c|c|c|c|c|c|c|}
\hline & \multicolumn{3}{|c|}{ Drug-ethanol } & \multicolumn{3}{|c|}{ Drug-tobacco } \\
\hline & Scope & Completeness & Consistency & Scope & Completeness & Consistency \\
\hline Tier 1 & LC, CP, SDI & LC, MM, DIF, FC & $\mathrm{MM}, \mathrm{CP}, \mathrm{DIF}$ & $\begin{array}{l}\text { MM, SDI, DIF, } \\
\mathrm{CP}\end{array}$ & $\mathrm{MM}$ & $\begin{array}{l}\text { DIF, SDI, } \\
\text { DIAM, MM }\end{array}$ \\
\hline Tier 2 & $\mathrm{FC}^{*}, \mathrm{MM}^{*}$ & $\mathrm{CP} \dagger, \mathrm{DIAM} \dagger$ & $\mathrm{FC}^{*}$, SDI $\ddagger$, LC & DIAM + , FC $\dagger$ & $\begin{array}{l}\text { DIAM } \ddagger \text { SDI†, FC*, } \\
\text { CP† }\end{array}$ & $\mathrm{N} / \mathrm{A}$ \\
\hline Tier 3 & DIF† & SDI† & $\mathrm{N} / \mathrm{A}$ & $\mathrm{N} / \mathrm{A}$ & DIF* & $\mathrm{N} / \mathrm{A}$ \\
\hline Tier 4 & DIAM* & $\mathrm{N} / \mathrm{A}$ & $\mathrm{N} / \mathrm{A}$ & $\mathrm{N} / \mathrm{A}$ & N/A & N/A \\
\hline
\end{tabular}

CP: Clinical Pharmacology; FC: Facts \& Comparisons; LC: Lexicomp; MM: Micromedex; DIAM: Drug Interactions Analysis and Management; DIF: Drug Interaction Facts; SDI: Stockley's Drug Interactions.

${ }^{*} p<0.05$ compared to next highest tier, $\uparrow p<0.001$ compared to next highest tier, $\ddagger p<0.01$ compared to next highest tier. 
Results of this study echo a previous investigation focused on drug-drug and drug-dietary supplement interactions in several key ways [10]. First, the previous investigation also identified that deficiencies in severity and level of certainty were the most common factors that drove differences in completeness. Both studies identified that the information is highly variable among resources with consistency scores ranging from about $32 \%$ to $83 \%$ in this study and from about $35 \%$ to $70 \%$ in the previous study. However, consistency and scope have improved compared to an earlier study [13]. Finally, Drug Interaction Facts, Facts \& Comparisons, Lexicomp, and Micromedex had the highest completeness scores in 2 past studies [10,11], which was similar to this study for drug-ethanol interactions, but not drug-tobacco interactions. One key difference was that this study yielded lower scope scores (range of about $21 \%$ to $85 \%$ for drugethanol and 0 to $56 \%$ for drug-tobacco) compared to previous investigations (about $67 \%$ to $97 \%$ and about $71 \%$ to $88 \%$ ), suggesting that, particularly for drugtobacco, clinically relevant interactions are not sufficiently addressed.

Strengths of this study included use of two independent data collectors with, anecdotally, few discrepancies that needed resolution, investigation into an important category of drug interactions that have not been addressed in previous studies [10-13], and use of seven highly regarded electronic and print point-of-care resources that are recommended by experts [21, 22].

There were also several important limitations. First, although our sample represented a crosssection of the most clinically relevant drug-ethanol and drug-tobacco interactions, not every potential interaction was evaluated. However, the sample size compared favorably to past studies [10-12]. Our sample size was potentially smaller than ideal for analyzing drug-tobacco completeness and consistency, primarily due to lower than expected scope scores. Additionally, we noted that data collection was simpler for resources such as Drug Interaction Facts, where information was provided in discrete, easily identifiable categories, compared to others, such as Stockley's Drug Interactions, where information was generally provided in narrative paragraphs. This could potentially lead to artificial differences in completeness scores.

Some previous studies have identified that it would be of interest to evaluate whether resources recommend specific alternate therapies [26, 27]; we did not evaluate alternatives, but this may be an appropriate topic for future investigation. Since we conducted the study using a cross-sectional design, we only analyzed each interaction at a single point in time and did not account for potential longitudinal changes. We attempted to maximize fair treatment of resources by evaluating an interaction in each of the seven resources on the same day. Finally, we noted that it had been several years since each of the three print resources had been updated. Impact of this limitation is expected to be minimal given the lack of newer drugs in our sample.

Future evaluations of resources for analyzing drug interactions should focus on other types of drug interactions with non-drug agents, such as food and illicit substances, that have not been previously examined. Additionally, content describing multidimensional interactions (i.e., interactions that are themselves altered by a third entity) have been minimally evaluated and warrant further study.

\section{ACKNOWLEDGMENTS}

The authors thank Thomas R. Smith, PharmD, $\mathrm{BCPP}$, for his contribution toward selecting the sample of interactions.

\section{COMPETING INTERESTS}

Robert D. Beckett is a paid editorial advisor consultant for Truven Health Analytics

(Micromedex, off-label uses), receiving estimated annual compensation less than $\$ 5,000$. His work on off-label uses does not involve review of drug interactions content. No funding was sought or received in support of this project. 


\section{REFERENCES}

1. World Health Organization. Global status report on alcohol and health: country profiles [Internet]. Geneva, Switzerland: The Organization [2014; cited Aug 21 2018]. $<$ http://www.who.int/substance_abuse/publications/glo bal_alcohol_report/msb_gsr_2014_2.pdf?ua=1>.

2. Substance Abuse and Mental Health Services Administration. 2015-2016 national surveys on drug use and health: model-based estimated totals (in thousands) (50 states and the District of Columbia) [Internet]. Rockville, MD: The Administration [Feb 2018; cited Aug 21 2018] <https://www.samhsa.gov/data/sites/default/files/cbhsqreports/NSDUHsaeTotal2016/NSDUHsaeTotals2016.pdf>.

3. Chan LN, Anderson GD. Pharmacokinetic and pharmacodynamic drug interactions with ethanol (alcohol). Clin Pharmacokinet. 2014 Dec;53(12):1115-36. DOI: http://dx.doi.org/10.1007/s40262-014-0190-x.

4. Anderson GD, Chan LN. Pharmacokinetic drug interactions with tobacco, cannabinoids and smoking cessation products. Clin Pharmacoknet. 2016 Nov;55(11):1353-68. DOI: http://dx.doi.org/10.1007/s40262-016-0400-9.

5. Furukawa MF, Spector WD, Rhona Limcangco M, Encinosa WE. Meaningful use of health information technology and declines in in-hospital adverse drug events. J Am Med Inform Assoc. 2017 Jul;24(4):729-36. DOI: http://dx.doi.org/10.1093/jamia/ocw183.

6. Sarkar U, Lopez A, Maselli JH, Gonzales R. Adverse drug events in U.S. adult ambulatory medical care. Health Serv Res. 2011 Oct;46(5):1517-33. DOI: http://dx.doi.org/10.1111/j.1475-6773.2011.01269.x.

7. Hakkarainen KM, Hedna K, Petzold M, Hagg S. Percentage of patients with preventable adverse drug reactions and preventability of adverse drug reactions - a meta-analysis. PLoS One. 2012 Mar;7(3):e33236. DOI: http://dx.doi.org/10.1371/journal.pone.0033236.

8. Hersh EV, Pinto A, Moore PA. Adverse drug interactions involving common prescription and over-the-counter analgesic agents. Clin Ther. 2007 Dec;29(11 supp 1):2477-97. DOI: http://dx.doi.org/10.1016/j.clinthera.2007.12.003.

9. Zevin S, Benowitz NL. Drug interactions with tobacco smoking: an update. Clin Pharmacokinet. 1999 Jun;36(6):425-38. DOI: http://dx.doi.org/10.2165/00003088-199936060-00004.

10. Patel RI, Beckett RD. Evaluation of resources for analyzing drug interactions. J Med Libr Assoc. 2016 Oct;104(4):290-5. DOI: http:/ / dx.doi.org/10.3163/1536-5050.104.4.007.

11. Clauson KA, Marsh WA, Polen HH, Seamon MJ, Ortiz BI. Clinical decision support tools: analysis of online drug information databases. BMC Med Inform Decis Mak. 2007 Mar;7:7. DOI: http:/ / dx.doi.org/10.1186/1472-6947-7-7.

12. Somogyi-Vegh A, Nyaka B, Vida RG, Lovasz A, Botz L. Comprehensive evaluation of drug interaction screening programs: discrepancies and concordances. Orvosi Hetilap. 2015 Mar;156(18):720-30. DOI: http://dx.doi.org/10.1556/OH.2015.30134.
13. Abarca J, Malone DC, Armstrong EP, Grizzle AJ, Hansten PD, Van Bergen RC, Lipton RB. Concordance of severity ratings provided in four drug interaction compendia. J Am Pharm Assoc. 2004 Mar-Apr;44(2):136-41. DOI: http://dx.doi.org/10.1331/154434504773062582.

14. Elsevier/Gold Standard. Clinical pharmacology drug interaction report [Internet]. Tampa, FL: Elsevier/Gold Standard [2018; cited 5 Jul 2018]. <http://www.clinicalpharmacologyip.com/Forms/Reports/intereport.aspx>.

15. Wolters Kluwer Health. Facts \& Comparisons ${ }^{\circledR}$ eAnswers [Internet]. St. Louis, MO: Wolters Kluwer Health [2018; cited 5 Jul 2018]. <http://online.factsandcomparisons.com>.

16. Wolters Kluwer. Lexicomp® interactions [Internet]. Hudson, OH: Wolters Kluwer [2018; cited 5 Jul 2018]. $<$ http://online.lexi.com/lco/action/interact>.

17. Truven Health Analytics. Micromedex® solutions drug interactions [Internet]. Greenwood Village, CO: Truven Health Analytics [2018; cited 27 Sep 2018]. $<$ https://www.micromedexsolutions.com/micromedex2/lib rarian>.

18. Hansten PD, Horn JR. Drug interactions analysis and management. St. Louis, MO: Wolters Kluwer Health; 2014.

19. Tatro DS, ed. Drug interaction facts 2015. St. Louis, MO: Wolters Kluwer Health; 2014

20. Baxter K, Preston CL, eds. Stockley's drug interactions. 10th ed. London, UK: Pharmaceutical Press; 2013.

21. Giovenale S, ed. Basic resources for pharmacy education [Internet]. Arlington, VA: American Association of Colleges of Pharmacy [2018; cited 5 Jul 2018].

$<$ http://connect.aacp.org/HigherLogic/System/Downloa dDocumentFile.ashx?DocumentFileKey=a82094a8-1aed6869-4b10-6d318046ccfa\&forceDialog=0>.

22. Shields KM, Park SK. Drug information resources. In: Drug information: a guide for pharmacists. New York, NY: McGraw Hill Education; 2018.

23. Indiana University School of Medicine. Drug interactions: Flockhart table: P450 drug interaction table [Internet]. Indianapolis, IN: The University [2016; cited 5 Jul 2018]. $<$ http://medicine.iupui.edu/clinpharm/ddis/maintable $/>$.

24. Montgomery AE, Beckett RD, Montagano KJ, Kutom S. Evaluation of point-of-care resources for dietary supplement information. J Evid-Based Integ Med. 2018 JanDec;23:251569DX18764844.

25. Polen HH, Zapantis A, Clauson KA, Jebrock J, Paris M. Ability of online drug databases to assist in clinical decision-making with infectious disease therapies. BMC Infect Dis. 2008 Nov;8:153. DOI: http://dx.doi.org/10.1186/1471-2334-8-153.

26. Floor-Schreudering A, Geerts AFJ, Aronson JK, Bouvy ML, Ferner RE, De Smet PAGM. Checklist for standardized reporting of drug-drug interaction management guidelines. Eur J Clin Pharmacol. 2014 Mar;70(3):313-8. DOI: http://dx.doi.org/10.1007/s00228-013-1612-7. 
27. Indermitte J, Erba L, Beutler M, Bruppacher R, Haefeli WE, Hersberger KE. Management of potential drug interactions in community pharmacies: a questionnaire-based survey in Switzerland. Eur J Clin Pharmacol. 2007 Mar;63(3):297-305. DOI: http://dx.doi.org/10.1007/s00228-006-0237-5.

28. IBM Analytics. IBM SPSS statistics. Version 24. Armonk, NY: IBM; 2016.

\section{AUTHORS' AFFILIATIONS}

Robert D. Beckett, rdbeckett@manchester.edu, https://orcid.org/0000-0001-6487-6683, Associate Professor of Pharmacy Practice and Director of the Drug Information Center, College of Pharmacy, Natural \& Health Sciences, Manchester University, Fort Wayne, IN

Curtis D. Stump, cdstump2018@manchester.edu, Doctor of Pharmacy Student, College of Pharmacy, Natural \& Health Sciences, Manchester University, Fort Wayne, IN

Megan A. Dyer, madyer2018@manchester.edu, Doctor of Pharmacy Student, College of Pharmacy, Natural \& Health Sciences,

Manchester University, Fort Wayne, IN

Received July 2018; accepted September 2018

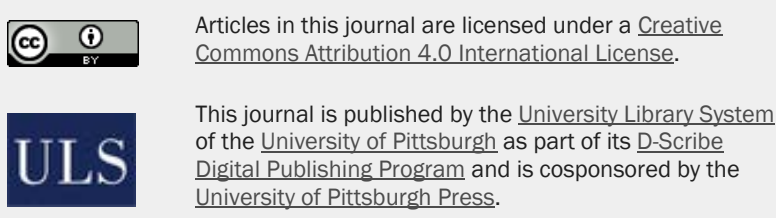

ISSN 1558-9439 (Online) 